\title{
Influence of Pre-Mating Plasma Prolactin Profile on Reproductive Performance of California doe rabbits
}

\begin{abstract}
Abdel-Khalek El-Sayed Abdel-Khalek ${ }^{\mathrm{a},}{ }^{*}$, Zeyad Kalaba ${ }^{\mathrm{b}}$, Helmy Zaghloul ${ }^{\mathrm{c}}$, Goerge Ezzate Younan $^{\mathrm{d}}$

${ }^{a}$ Department of Animal Production, Faculty of Agriculture, Mansoura University, Mansoura, 35516, Egypt, ${ }^{b}$ Department of Poultry Production, Faculty of Agriculture, Mansoura University, Mansoura, 35516, Egypt, ' Institute of Agriculture co-operation, Shobra El-Khima, Egypt, ${ }^{\mathrm{d}}$ Animal Production Research Institute, Agricultural Research Center, Egypt; abdelkhalk2004@yahoo.com (A.E.A.); kalaba@mans.edu.eg (Z.K.); Helmyzaghlool@yahoo.com (H.Z.); ggezzate@yahoo.com (G.E.Y.) *Correspondence: abdelkhalk2004@yahoo.com
\end{abstract}

\begin{abstract}
Ovulation failure was associated with a reduction in pre-mating concentrations of oestradiol-17 $\beta$ and prolactin (PRL). The present study aimed to evaluate whether pre-mating PRL levels have a role on the reproductive efficiency of doe rabbits. A total of 78 multiparous California does ( $2^{\text {nd }}$ parity) were divided, according to plasma pre-mating PRL, into five categories, $>20-25$, $>25-30,>30-35,>35-40$, and $>40-45 \mathrm{ng} / \mathrm{ml}$. Does in all categories were naturally mated and kindled, then their reproductive measurements and progesterone (P4) levels were determined. Results show that pre-mating PRL averaged 23.60 $\pm 0.78,28.00 \pm 0.83,33.46 \pm 0.43,38.17 \pm 0.49$ and $41.98 \pm 0.68 \mathrm{ng} / \mathrm{ml}$ in five categories $(p<0.05)$, respectively, representing the highest distribution $(38.5 \%)$ in the $3^{\text {rd }}$-category. Live body weight of doe rabbits, at mating, pregnancy, and parturition increased $(p<0.05)$ with increasing pre-mating PRL level. The number of services, litter size, and pregnancy rate increased $(p<0.05)$ by increasing PRL levels. Reproductive traits and P4 level at mid-pregnancy of does, and average weight of kits at birth increased $(p<0.05)$ by increasing PRL levels. The pre-mating PRL profile is important for the identification of reproductive performance in doe rabbits.
\end{abstract}

Keywords: litter size; prolactin; progesterone; pregnancy; rabbits

\section{Introduction}

Prolactin (PRL) is a single-chain protein containing 199 amino acids [1] and produced in the lactotropes of the anterior pituitary gland. It has a wide range of biological actions in various species and is primarily regulated by dopamine secreted from the hypothalamus [2]. Dopamine is a PRL inhibiting factor [3]. Prolactin is related to pregnancy and lactation but has recently a vital role in the reproduction of non-pregnant females of different species. During puerperal lactation, PRL levels fluctuate widely owing to their release in association with suckling [4]. During pregnancy, circulating levels of PRL gradually rise to reach a maximum at term [5]. After delivery, PRL levels fall but basal concentrations do not reach the non-pregnant range until at least 2 weeks postpartum [6].

Rabbits with reduced pre-mating levels of oestradiol-17 $\beta$ and PRL were associated with ovulation failure. Rabbits that failed to ovulate had significantly lower pre-mating concentrations of PRL than that ovulated at this time. However, no significant differences in PRL concentrations were observed during the pre-ovulatory period between rabbits ovulating on different post-partum days, despite an apparent equal suckling stimulus, litter size, and weight [7].

In non-pregnant animals, previous research has indicated that PRL is actively involved in reproduction in mares. The level of PRL increased during the transition from the anovulatory to 
the breeding season, being the highest during the breeding season [8]. In another study, administration of recombinant porcine PRL daily to seasonally anovulatory pony mares resulted in ovulation or corpus luteum (CL) formation [9].

Given the positive response of reproduction in mars to the profile of PRL during the breeding season, the role of a pre-mating profile of PRL is of limited value for identifying possible variability in the fertility of doe rabbits. These findings prompted us to evaluate the possible effects of pre-mating prolactin profile on the reproductive efficiency of doe rabbits and the litter characteristics of their offspring.

\section{Materials and Methods}

The experimental work was carried out in a private Rabbit Production Farm in Zian Region, Dakahlyia governorate, Egypt, from December 2019 to March 2020.

\subsection{Animals}

A total of 78 mature multiparous California doe rabbits (6-7 mo of age and $2.8-3.1 \mathrm{~kg}$ body weight), as well as 20 fertile California rabbit bucks (10-13 mo of age and 3.5-4.1 kg body weight), were used in this study. All animals were healthy and clinically free of external parasites. All does and bucks were housed in a naturally ventilated building and kept individually in flat deck cages $(50 \times 60 \times 40 \mathrm{~cm})$ equipped with automatic water dispensers and supplied only for does with internal nest boxes.

Animals were fed ad-libitum on a commercial diet $(10.5 \mathrm{MJ} \mathrm{ME} / \mathrm{kg}, 18.5 \% \mathrm{CP}$, and $12.5 \%$ $\mathrm{CF}$ according to their physiological condition. Drinking water was available from nipple drinkers. Does and bucks were maintained under the same management system and under similar normal conditions. Cages and nest boxes were cleaned and disinfected regularly before each kindling. Urine and feces were dropped from the cages on the floor and were cleaned daily in the morning.

\subsection{Experimental design}

At the beginning of the experimental period, blood samples were collected from doe rabbits $(\mathrm{n}=78)$ immediately following the $1^{\text {st }}$ parity. Within $24 \mathrm{~h}$ of parturition, receptive doe rabbits were mated and plasma PRL concentration was determined for all doe rabbits. Doe rabbits were divided, according to plasma PRL levels, into five PRL categories (A-E), involving $>20-25,>25-30,>30$ $35,>35-40$ and $>40-45 \mathrm{ng} / \mathrm{ml}$. Pregnancy diagnosis was performed on days 10-12 post-mating, and doe rabbits that failed to conceive were re-mated.

\subsection{Reproductive traits}

On the day of mating, doe rabbits were weighed, transferred to the cage of buck, and returned to their cage after mating. Each mated doe was palpated 10-12 d post-mating to diagnose pregnancy and the pregnancy rate was calculated. Rabbits that failed to conceive following the $1^{\text {st }}$ mating were returned to re-mating and the number of services per conception was recorded. On day 27 of pregnancy, the nest boxes were supplied with wooden straw to help the doe in preparing a warm comfortable nest for the kits. After kindling, gestation period and litter size (total and live) per doe were calculated at birth and weaning. Live body weight of does on days 9, 14, and 28 of pregnancy and at kindling (within $12 \mathrm{~h}$ ). Kit weight at birth, the sex ratio at weaning, and viability rate at birth and weaning were recorded. 


\subsection{Blood samples and hormonal assay}

Blood samples were collected by puncture of the ear vein into heparinized clean test tubes and immediately centrifuged (3000 rpm for $15 \mathrm{~min}$ ), then, blood plasma was separated and stored at $-20^{\circ} \mathrm{C}$ until hormonal assay. Blood samples were collected from all does $(n=78)$ pre-mating for PRL determination and on Days 15 and 27 of gestation from seven doe rabbits proven pregnant in each PRL category for progesterone $\left(\mathrm{P}_{4}\right)$ assay.

Pre-mating PRL concentration in blood plasma was determined using PRL kit (DiaMetra S.r. I Headquarter: Via Garibaldi, 18-20090 SEGRATE "MI", Italy) according to Shome and Parlow [10]. Plasma concentrations of $\mathrm{P}_{4}$ on Days 15 and 27 of pregnancy were determined by using a $\mathrm{P}_{4}$ kit (Oxis International, Inc. 323 Vintage Park Dr. Foster City, CA 94404) according to Ross et al. [11]. The intra- and inter-assay coefficients of variation were $51 ; 8-3 \%$ and $6 ; 13 \%$ for the PRL and P4 assays, respectively.

\subsection{Statistical analysis}

Data were statistically analyzed using the computer program of SAS [12] using one-way analysis of variance (ANOVA) by GLM procedures. The significant differences were separated by Duncan Multiple Range Test and set at $p<0.05$ level. A Chi-square test was used for statistical analysis of pregnancy rate, viability rate, and sex ratio. Pearson correlation coefficients of premating PRL level with reproductive traits of does were done.

\section{Results}

\subsection{Pre-mating Prolactin Profile}

Pre-mating plasma PRL ranged between $>20$ and $45 \mathrm{ng} / \mathrm{ml}$ in five categories, averaging the lowest values in category $\mathrm{A}$, and the highest values in category $\mathrm{E}(p<0.05)$. Does in category $\mathrm{C}$ $(>30-35 \mathrm{ng} / \mathrm{ml})$ represented the highest frequency distribution $(38.5 \%)$, while those in category $\mathrm{E}$ ( $>40-45 \mathrm{ng} / \mathrm{ml})$ had the lowest distribution (12.8\%, Table 1).

\subsection{Live Body Weight of Doe Rabbits}

Live boy weight (LBW) of does gradually increased after mating and during gestation period with marked drop at kindling, being the heaviest in categories D and E, moderate in category $\mathrm{C}$, and the lightest in categories $\mathrm{A}$ and $\mathrm{B}(p<0.05$, Figure 1$)$.

The correlation coefficients between pre-mating PRL level in all categories and LBW of does was significantly positive at all reproductive stages, being the highest on Day 14 and 28 of gestation $(\mathrm{r}=0.820 ; \mathrm{r}=0.818 ; p<0.05)$ and the lowest at kindling $(\mathrm{r}=0.639, p<0.05)$.

\subsection{Reproductive Performance of Doe Rabbits}

Reproductive traits including the number of mating cases per conception, pregnancy rate after the $1^{\text {st }}$ mating, litter size (live and dead) of does, and viability rate and average body weight of their kits increased $(p<0.05)$ by increasing PRL category, being the best in categories D and E, and the lowest in category A. However, gestation period length was nearly similar in all PRL categories (Table 2). 


\subsection{Litter characteristics}

Litter characteristics at weaning in terms of litter size, and the number of males and females was increased $(p<0.01)$ by increasing PRL level, being the highest with does in categories D and E. However, the sex ratio of kits at weaning was not affected by PRL level (Table 3).

Kit viability rate at birth showed an inconsistent trend $(p<0.05)$ of change with pre-mating PRL level. Viability rate at weaning showed a gradual increase $(p<0.05)$ by increasing PRL level up to category $\mathrm{D}$, then decreased ( $p \geq 0.05$ ) with category E (Fig. 3).

\subsection{Progesterone profile during gestation}

The average plasma $\mathrm{P}_{4}$ concentration at mid-pregnancy (15 days) increased $(p<0.05)$ by increasing pre-mating PRL level up to the maximal level with categories D and E. Concentration $\mathrm{P}_{4}$ of at late pregnancy (27 days) was not affected by pre-mating PRL category. In all PRL categories, the $\mathrm{P}_{4}$ level was higher at mid-pregnancy than at late pregnancy (Fig. 4).

\section{Discussion}

The current study aimed to identify the possible effects of pre-mating PRL profile on reproductive efficiency of multiparous doe rabbits ( $2^{\text {nd }}$ parity) and litter characteristics of their offspring. The obtained results cleared pre-mating PRL levels of different categories between $23.60 \pm 0.78$ and $41.98 \pm 0.68 \mathrm{ng} / \mathrm{ml}$, and the differences among categories were significant $(p<$ 0.05). Category $\mathrm{C}$ of PRL level of $33.46 \pm 0.43 \mathrm{ng} / \mathrm{ml}$ represented the highest distribution among categories. Also, there is a marked relationship was cleared between pre-mating PRL level and LBW of does. Does in all PRL categories showed a similar trend of increase in LBW from mating up to kindling by increasing pre-mating PRL. Does were heavier with high than low pre-mating PRL categories, whereas does were the heaviest in categories D and E with the highest PRL levels $(>35-45 \mathrm{ng} / \mathrm{ml})$, and the lightest in categories A and B with the lowest PRL levels $(>20-30 \mathrm{ng} / \mathrm{ml})$. Pre-mating PRL and LBW were $33.46 \mathrm{ng} / \mathrm{ml}$ and $3.18 \mathrm{~kg}$ in $38.5 \%$ of does (category C), and 41.98 $\mathrm{ng} / \mathrm{ml}$ and $3.41 \mathrm{~kg}$ in $12.8 \%$ of does (category E). This relationship was indicated by the recorded positive correlation between pre-mating PRL level and LBW of does at mating $(\mathrm{r}=0.778, p<$ 0.001). Moreover, pre-mating PRL correlated with LBW of does during gestation $(\mathrm{r}=0.780-0.818$, $p<0.001)$ and kindling $(\mathrm{r}=0.639, p<0.001)$. These findings may suggest that LBW of does at mating is important to reflect a higher PRL profile at this stage of reproduction.

Regarding the relationship between pre-mating PRL category and reproductive performance, our results indicated remarkable improvement in most reproductive traits by increasing pre-mating PRL in association with increasing doe LBW at mating. This was proved in categories D and E with the highest pre-mating PRL profile and heaviest does at mating, whereas does in these categories showed the best reproductive traits and weight of their kits as compared to categories A-C. These findings are in association with positive correlation between pre-mating PRL and pregnancy rate $(\mathrm{r}=0.387, p<0.05)$, litter size as total and live at birth and weaning $(\mathrm{r}=0.779$ and $\mathrm{r}=0.670, p<0.001)$. It is of interest to observe that the pregnancy rate had a positiveweak correlation doe LBW $(\mathrm{r}=0.175, \mathrm{P} \geq 0.05)$. These results may indicate an association between high pre-mating PRL and improving pregnancy rate and litter size of does. However, improving litter size may be associated with PRL level and LBW of does at mating. This relation was indicated 
by highly significant $(p<0.001)$ and strong correlations between LBW of does at mating and litter size as total $(\mathrm{r}=0.859)$, live at birth $(\mathrm{r}=0.754)$, and weaning $(\mathrm{r}=0.813)$.

Our results showed that kit viability rate at weaning not at birth increased by increasing premating PRL but did not differ ( $p \geq 0.05)$ between high PRL categories (D and E) compared with low PRL categories. These findings may suggest an association of PRL concentration at mating and during the suckling period. Importantly, increasing PRL for initiation of lactation and consequently higher viability of kits during the suckling period.

The role of PRL level during the suckling period was evaluated by several authors, in terms of pronounced adverse effects on the reproductive performance of rabbits. Also, an increase of sexual receptivity during the first and last days of the lactation period, occurred under low plasma PRL levels, which is implicated in the receptivity inhibition was observed. This effect could be caused by the antagonism between increased plasma PRL concentrations during the suckling period [13], and the estrogenic effect on receptivity described [14]. About the beneficial effects of PRL level at mating on reproductive performance of doe rabbits, plasma pre-ovulatory PRL concentration was higher for ovulating than in non-ovulating and nulliparous doe rabbits [7]. This finding is in agreement with our results concerning pre-mating PRL of does.

After delivery, PRL levels fall but basal concentrations do not reach the non-pregnant range until at least 2 weeks postpartum [6]. Thus, we expected a higher PRL level at mating immediately after parturition than few days after parturition. This level may have a beneficial impact on the reproductive performance of rabbits with high PRL levels at mating. In this way, PRL has a wide range of biological actions in various species. In an early report, PRL increases at puberty, but only to a minor degree compared with LH and FSH. Also, the estrogen experienced at puberty is stimulatory to PRL secretion. Prolactin has been shown to increase LH receptors on granulosa and luteal cells of females $[15,16]$. In rats, suppression of PRL retarded normal follicular development and delayed puberty [17]. Previous research has indicated that PRL is also actively involved in reproduction in mares. Horses have higher PRL levels during the breeding season, with mares having the highest levels. Mares undergoing the transition from the anovulatory season to the breeding season experience increases in several hormones, including PRL [8]. Several research groups have shown that increasing PRL in mares in winter aids in the development of follicles and, in some cases, ovulation. An increase in PRL concentrations after administration of dopamine antagonists was reported [18], and an increase in PRL levels, either by a dopamine antagonist administration or by injection of bovine PRL, stimulated follicular growth positively and rapidly [19]. Also, [9] reported that daily administration of recombinant porcine PRL to seasonally anovulatory pony mares resulted in ovulation or corpus luteum (CL) formation.

Ovulation failure in rabbits was associated with an absence of the pre-ovulatory LH surge and a reduction in pre-mating concentrations of estradiol-17 $\beta$ and PRL. Does failing to ovulate on day 14 post-partum exhibited no preovulatory LH surge and had significantly $(\mathrm{P}<0.05)$ lower premating concentrations of oestradiol-17 $\beta$ and prolactin than those ovulating at this time. Average PPRL was $41.6,15.5$, and $16.3 \mathrm{ng} / \mathrm{ml}$ in the blood plasma of ovulating, non-ovulating and no mated rabbit does, respectively. However, no significant differences in PRL concentrations were observed during the pre-ovulatory period between doe rabbits ovulating on days 1 and 14 post-partum [7]. Chronic prolactin treatment promotes cholesterol storage and enhances the sensitivity of the ovary to LH in intact rabbits. In such animals, chronic prolactin treatment causes hypertrophy of the 
ovarian interstitial tissues but does not induce progestin release in the absence of estrogen or LH. Prolactin acts specifically on the rabbit ovary to maintain the steroid-producing capacity as well as the morphology of the interstitial tissues [20]. Enhancing the reproductive performance of high PRL levels at mating may be attributed to the immune action of PRL on the health and immunity of doe rabbits at mating. In this context, PRL activates thymocytes and lymphocytes as well as the secretion of the thymic hormone "thymulin" $(21,22)$.

It is of interest to note that $\mathrm{P}_{4}$ level during mid-pregnancy increased by increasing PRL level in association with litter size (number of CLs) of each PRL category. Such a trend reflected a strong and positive correlation of premating PRL with P4 at mid-pregnancy $(\mathrm{r}=0.809, p<0.001)$. At late pregnancy, $\mathrm{P}_{4}$ level decreased by increasing PRL in association with the incidence of CL regression at the end of gestation period in all categories, but the differences were not significant reflecting a negative correlation with $\mathrm{P} 4$ at late pregnancy $(\mathrm{r}=-0.546, p<0.001)$.

Based on the foregoing findings and correlations, pre-mating PRL profile is important for the identification of reproductive performance of doe rabbits with different PRL levels. Pre-mating PRL level increased by advancing parity and threshold level of pre-mating PRL in rabbits is required for fertility prediction.

\section{References}

[1] Nett, T.M. Reproductive peptide and protein hormones. in: Equine Reproduction. A. McKinnon and J. Voss, ed. Williams \& Wilkins, Media, PA, 1993; pp. 110.

[2] Hadley, M.E. Endocrinology, Prentice Hall, Inc., Upper Saddle River, New Jersey, 2000; pp 97-99, 517-518, 525, www.biblio.com/9780130803566.

[3] Ben-Jonathan, N.J.E. Dopamine: a prolactin-inhibiting hormone. Endocr. Rev. 1985, 6, Issue 4, 564-589, doi.org/10.1210/edrv-6-4-564.

[4] Hwang, P.; Guyda, H.; Friesen, H. A radioimmunoassay for human prolactin. PNAS August 1, 1971, 68 (8) 1902-1906, doi.org/10.1073/pnas.68.8.1902.

[5] Ajibola, A.; Chamunorwa, J.P.; Erlwanger, K.H. Nutraceutical values of natural honey and its contribution to human health and wealth. Nutr. Metab. (Lond) 2012, 9, 61, doi.org/10.1186/1743-7075-9-61.

[6] McNeilly, A.s. Lactation and the physiology of prolactin secretion. Postgrad. Med. J. 1965, 51, 231-235, doi.org/10.1136/pgmj.51.594.231.

[7] Lamb, I.; Strachan, W.; Henderson, G.; Atkinson, T.; Lawson, W.; Partridge, G.; Fuller, M.; Racey, P. Effects of reducing the remating interval after parturition on the fertility and plasma concentrations of luteinizing hormone, prolactin, oestradiol-17 $\beta$ and progesterone in lactating domestic rabbits. J. Reprod. Fert. 1991, 92, 281-289, doi.org/10.1530/jrf.0.0920281.

[8] Thompson D.; Garza, F.; George, R.L.; Rabb, M.; Barry, B.; French, D.D. Relationships among $\mathrm{LH}, \mathrm{FSH}$, and prolactin secretion, storage, and response to secretagogue and hypothalamic GnRH content in ovariectomized pony mares administered testosterone, dihydrotestosterone, estradiol, progesterone, dexamethasone, or follicular fluid. Domest. Anim. Endocrinol. 1991, 8, 189-199, doi.org/10.1016/0739-7240(91)90055-o.

[9] Thompson, D.; Johnson, L.; George, R.L.; Garza F. Concentrations of prolactin, luteinizing hormone and follicle-stimulating hormone in pituitary and serum of horses: effect of sex, season and reproductive state. J. Anim. Sci. 1986, 63, 854-860, doi.org/10.2527/jas1986.633854x. 
[10] Shome, B.; Parlow, A. Human follicle stimulating hormone (hFSII): first proposal for the amino acid sequence of the a-subunit of human luteinizing hor-mone (hLHa). J. Clin. Endocrinol. Metab. 1974, 39, 199-202, doi.org/10.1210/jcem-39-1-199.

[11] Ross, G.T., Vande Wiele, R.L., and Frantz, A.G. The ovaries and the breasts. In: Williams, R.H. (ed.) Textbook of Endocrinology, W.B. Saunders Co., Philadelphia, 1981, 355-411.

[12] SAS. SAS/STAT User's Guide: Version 9.1.3. 2004, SAS Institute, Cary, NC.

[13] Ubilla, E.; Alvarin, J.; Esquifino, A.; Agrasal, C. Effects of induction of parturition by administration of a prostaglandin F2 $\alpha$ analogue in rabbits: possible modification of prolactin, LH and FSH secretion patterns. Anim. Reprod. Sci. 1992, 27, 13-20. doi.org/10.1016/0378-4320(92)90066-M.

[14] Hudson, R.; González-Mariscal, G.; Beyer, C.J.H. Chin marking behavior, sexual receptivity, and pheromone emission in steroid-treated, ovariectomized rabbits. Horm. Behav. 1990, 24, 1-13, doi.org/10.1016/0018-506X(90)90022-P.

[15] Jones, P.B.; Hsueh, A.J.J.E.; Regulation of progesterone-metabolizing enzyme by adrenergic agents, prolactin, and prostaglandins in cultured rat ovarian granulosa cells. Endocrinology. 1981, 109,1347-1354, https ://doi.org/10.1210/endo-109-5-1347.

[16] Advis, J.; White, S.S.; Ojeda, S.J.E. Delayed puberty induced by chronic suppression of prolactin release in the female rat. Endocrinol. 1981, 109, 1321-1330, doi: 10.1210/endo109-5-1321.

[17] Besognet, B.; Hansen, B.; Daels, P.J.T. Induction of reproductive function in anestrous mares using a dopamine antagonist. Theriogenology 1997, 47, 467-480, doi.org/10.1016/S0093691X(97)00005-8.

[18] Van Straalen, R.; Zeilmaker, G.J. Observations on the effects of prolactin on LH-receptors and steroidogenesis in corpus luteum and testis of the hypophysectomized rat. Eur. J. Endocrinol. 1982, 99, 437-442, doi.org/10.1530/acta.0.0990437.

[19] Nequin, L.; King, S.; Johnson, A.L.; Gow, G.; Ferreira-Dias, G.M. Prolactin may play a role in stimulating the equine ovry during the spring reproductive transition. J. Equine Vet. Sci. 1993, 13, 631-635, doi.org/10.1016/S0737-0806(07)80391-1.

[20] Hilliard, J.; Spies, H.G.; Lucas, L.; Sawyer, C.H.J.E. Effect of prolactin on progestin release and cholesterol storage by rabbit ovarian interstitium. Endocrinology. 1968, 82, 122-131. doi:10.1210/endo-82-1-122.

[21] Spangelo, B.L.; Gorospe, W.C. Role of the cytokines in the neuroendocrine-immune system axis. Frontiers in Neuroendocrinology 1995, 16,1-22, doi:10.1006/frne.1995.1001.

[22] Kruger, T.E.; Smith, L.R.; Harbour, D.V.; Blalock, J.E. Thyrotropin: An endogenous regulator of the in vitro immune response. J. Immunol. 1989, 142, 744-747, PMID: 2492328 


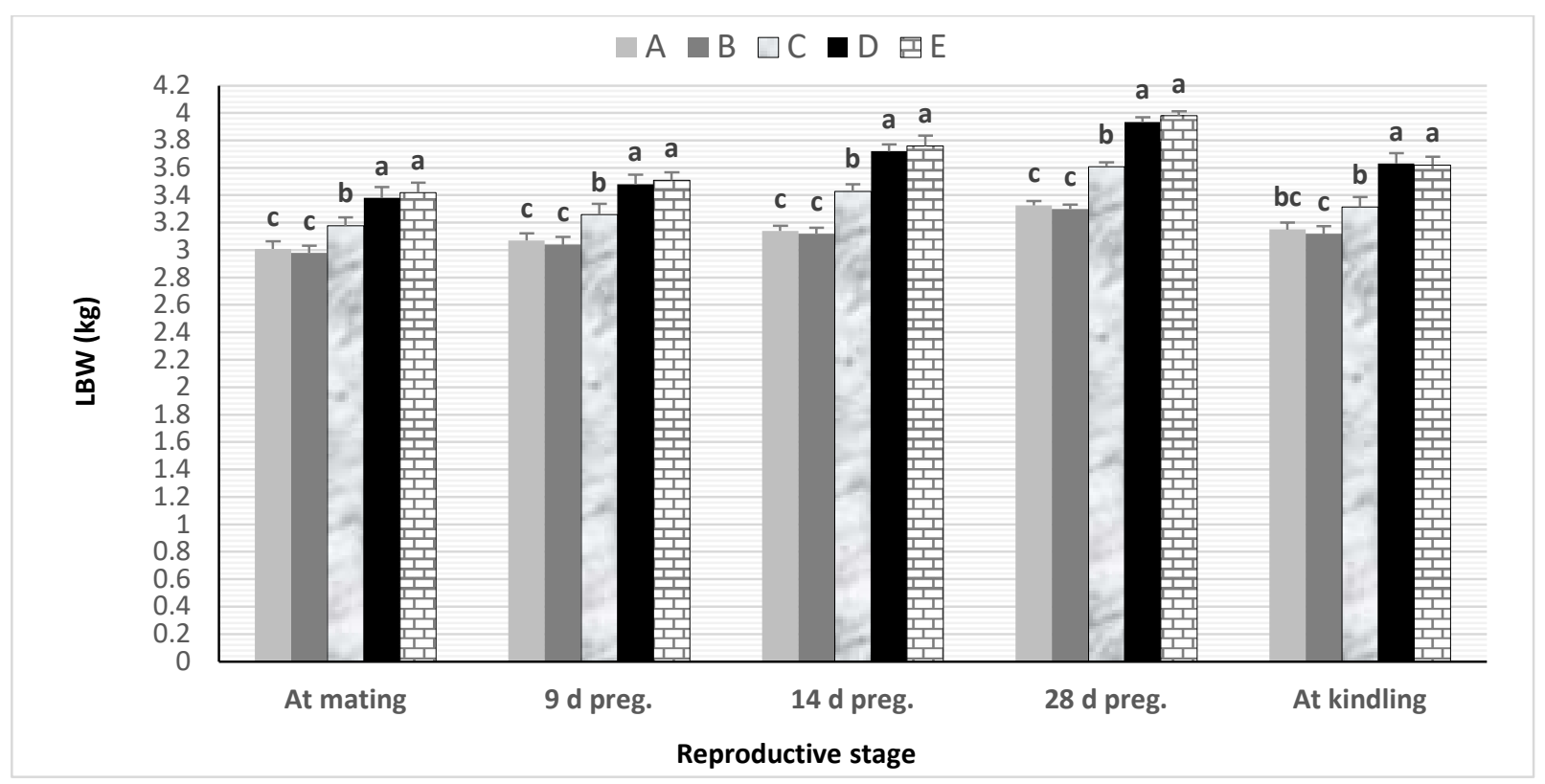

Figure 1. Change in live body weight of doe rabbits from mating up to kindling. (a,b,c: significant category differences at $p<0.05$ )

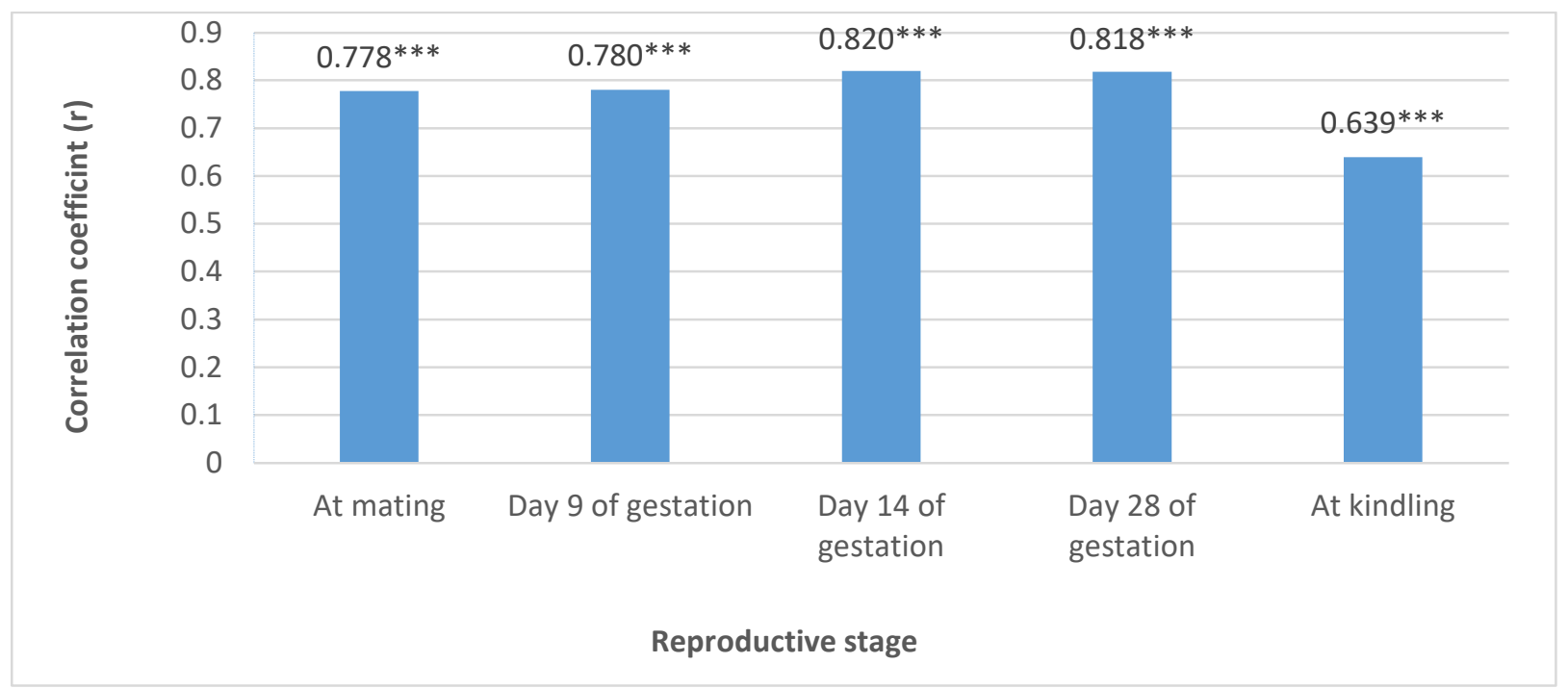

Figure 2. Correlation coefficients between PRL level and doe live body weight at different reproductive stages. $(* * *$ significant at $p<0.001)$ 


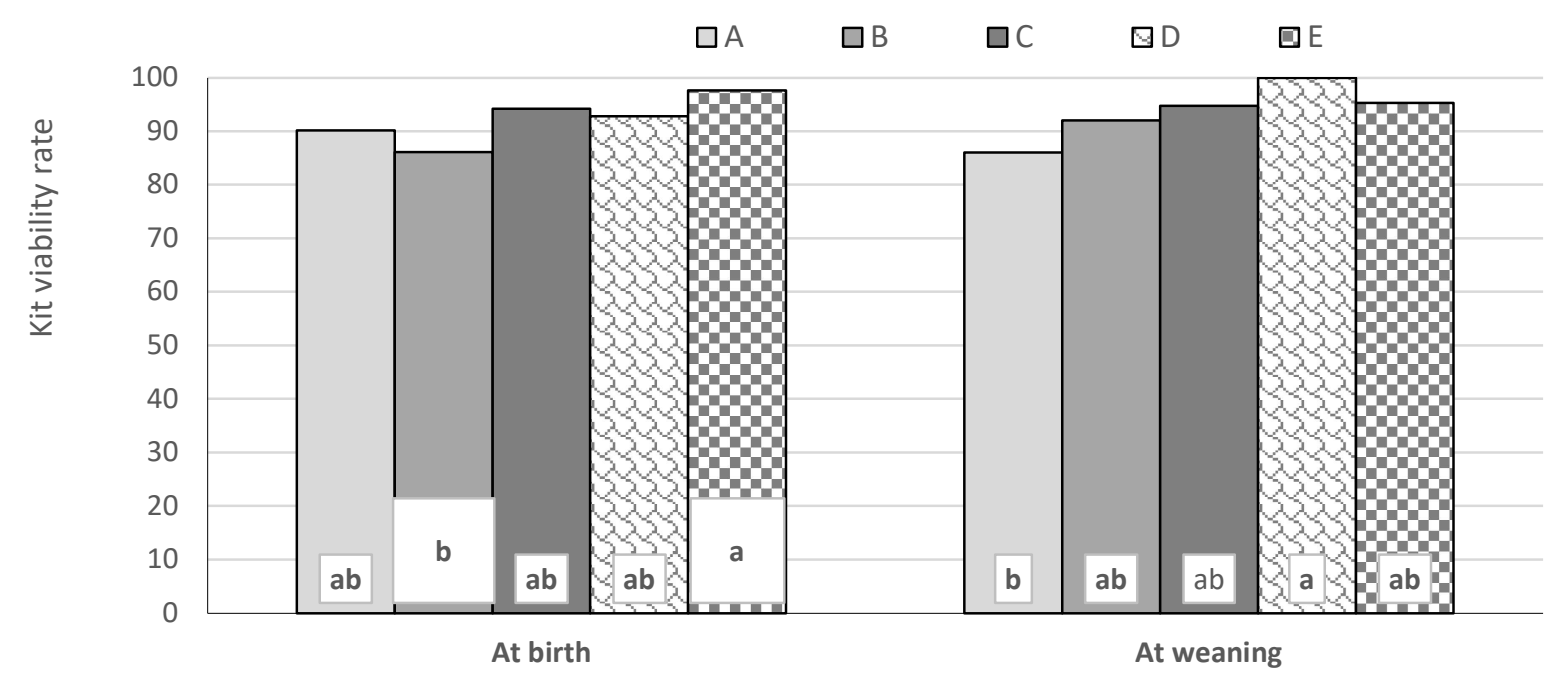

Figure 3. Kit viability rate at birth and weaning as affected by PRL category. (a,b: significant category differences at $p<0.05$ )

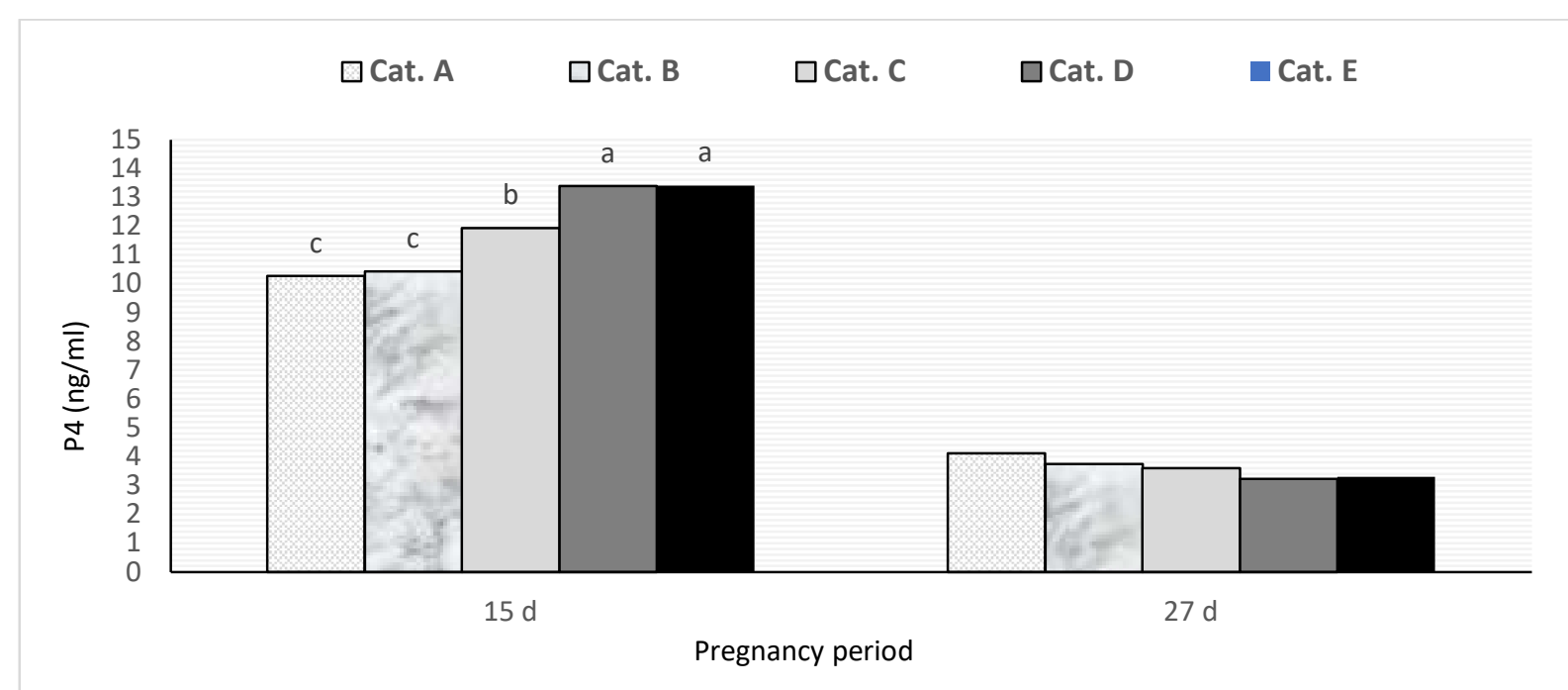

Figure 4. The concentration of progesterone in the blood plasma of does in different PRL categories at mid-and late pregnancy. (a,b,c: significant category differences at $p<0.05$ Table 1. Pre-mating plasma PRL profile of doe rabbits.

\begin{tabular}{ccccc}
\hline $\begin{array}{c}\text { Pre-mating PRL } \\
\text { category }\end{array}$ & \multicolumn{2}{c}{ Doe rabbits } & \multicolumn{2}{c}{ Pre-mating PRL (ng/ml) } \\
\cline { 5 - 6 } A & 14 & 17.9 & $>20-25$ & Mean \pm SE \\
B & 12 & 15.4 & $\geq 25-30$ & $23.60 \pm 0.78^{\mathrm{e}}$ \\
C & 30 & 38.5 & $>30-35$ & $28.00 \pm 0.83^{\mathrm{d}}$ \\
D & 12 & 15.4 & $>35-40$ & $33.46 \pm 0.43^{\mathrm{c}}$ \\
E & 10 & 12.8 & $>40-45$ & $41.98 \pm 0.68^{\mathrm{a}}$ \\
\hline
\end{tabular}

a,b ...e. : Means denoted within the same column with different superscripts are significantly different at $p<0.05$.

Table 2. Reproductive traits of doe rabbits as affected by the PRL category. 


\begin{tabular}{|c|c|c|c|c|c|}
\hline \multirow{2}{*}{$\begin{array}{c}\text { PRL } \\
\text { category }\end{array}$} & \multicolumn{2}{|c|}{ Mating cases per Pregnancy } & \multirow{2}{*}{$\begin{array}{l}\text { Gestation } \\
\text { period (d) }\end{array}$} & Litter size at birth & \multirow{2}{*}{$\begin{array}{c}\text { Average kit } \\
\text { weight at birth (g) }\end{array}$} \\
\hline & conception (n) & rate ${ }^{+}$ & & Total & \\
\hline $\mathrm{A}$ & $1.14 \pm 0.16^{\mathrm{ab}}$ & $85^{\mathrm{b}}$ & $31.3 \pm 0.39$ & $5.71 \pm 0.31^{\mathrm{c}} 5.14 \pm 0.28^{\mathrm{b}}$ & $55.71 \pm 2.227^{\mathrm{c}}$ \\
\hline B & $1.00 \pm 0.00^{\mathrm{b}}$ & $100^{\mathrm{a}}$ & $31.0 \pm 0.47$ & $5.80 \pm 0.39^{c} 5.00 \pm 0.58^{b}$ & $.000^{\mathrm{c}}$ \\
\hline $\mathrm{C}$ & $1.20 \pm 0.10^{\mathrm{a}}$ & $80^{\mathrm{b}}$ & 20 & $6.80 \pm 0.27^{\mathrm{b}} 6.40 \pm 0.40^{\mathrm{b}}$ & $0.581^{b}$ \\
\hline $\mathrm{D}$ & $1.00 \pm 0.00^{\mathrm{b}}$ & $100^{\mathrm{a}}$ & $30.8 \pm 0.18$ & $8.40 \pm 0.22^{\mathrm{a}} 7.80 \pm 0.45^{\mathrm{a}}$ & $66.00 \pm 0.931^{\mathrm{a}}$ \\
\hline $\mathrm{E}$ & $1.00 \pm 0.00^{\mathrm{b}}$ & $100^{\mathrm{a}}$ & $31.6 \pm 0.22$ & $8.60 \pm 0.37^{\mathrm{a}} 8.40 \pm 0.47^{\mathrm{a}}$ & $65.00 \pm 0.000^{\mathrm{a}}$ \\
\hline
\end{tabular}

a,b,c: Means denoted within the same column with different superscripts are significantly different at $p<0.05 .{ }^{+}$Following the $1^{\text {st }}$ mating.

Table 3. Litter characteristics and sex ratio of does at weaning in different PRL categories.

\begin{tabular}{ccccc}
\hline $\begin{array}{c}\text { PRL } \\
\text { category }\end{array}$ & $\begin{array}{c}\text { Litter size at } \\
\text { weaning }\end{array}$ & $\begin{array}{c}\text { Number of } \\
\text { males/doe }\end{array}$ & $\begin{array}{c}\text { Number of } \\
\text { females/doe }\end{array}$ & $\begin{array}{c}\text { Sex ratio } \\
\text { (Male: female) }\end{array}$ \\
\hline A & $4.42 \pm 0.222^{\mathrm{c}}$ & $2.42 \pm 0.222^{\mathrm{b}}$ & $2.00 \pm 0.000^{\mathrm{b}}$ & 54.3 \\
B & $4.60 \pm 0.425^{\mathrm{c}}$ & $2.60 \pm 0.425^{\mathrm{b}}$ & $2.00 \pm 0.000^{\mathrm{b}}$ & 54.7 \\
C & $6.07 \pm 0.333^{\mathrm{b}}$ & $4.00 \pm 0.340^{\mathrm{a}}$ & $2.07 \pm 0.274^{\mathrm{b}}$ & 65.1 \\
D & $7.80 \pm 0.456^{\mathrm{a}}$ & $4.20 \pm 0.684^{\mathrm{a}}$ & $3.60 \pm 0.559^{\mathrm{ab}}$ & 53.3 \\
E & $8.00 \pm 0.294^{\mathrm{a}}$ & $4.00 \pm 0.294^{\mathrm{a}}$ & $4.00 \pm 0.294^{\mathrm{a}}$ & 50.0 \\
\hline
\end{tabular}

a,b,c: Means denoted within the same column with different superscripts are significantly different at $p<0.05$.

Table 4. Personal correlation coefficients of PRL profile or LBW at mating with different reproductive traits

\begin{tabular}{|c|c|c|}
\hline \multirow{2}{*}{ Item } & \multicolumn{2}{|c|}{ Correlation coefficient (r) } \\
\hline & Pre-mating PRL & Pre-mating LBW \\
\hline Pregnancy rate & $0.387^{*}$ & 0.175 \\
\hline Total litter size at birth & $0.779 * * *$ & $0.859 * * *$ \\
\hline Live litter size at birth & $0.670 * * *$ & $0.754 * * *$ \\
\hline Weaning litter size & $0.772 * * *$ & $0.813 * * *$ \\
\hline Average kit weight at birth & $0.772 * * *$ & $0.806 * * *$ \\
\hline $\mathrm{P} 4$ at mid-pregnancy ${ }^{+}$ & $0.809 * * *$ & $0.810 * * *$ \\
\hline $\mathrm{P} 4$ at late pregnancy ${ }^{++}$ & $-0.546 * * *$ & $-0.454 * *$ \\
\hline
\end{tabular}

